that he would forget what he wished to say. His wife asserted that he had always had some trouble in speaking. He could not picture words. He could spell, but could not tell the number of letters in words of even three letters without counting on his fingers. He could repeat the Lord's prayer correctly, but brokenly and hurriedly. Repetition was much affected; voluntary writing was bad and copying even worse. He had a clcar understanding of the use of articles, and there was no astereognosis. He could carry out simple instructions, and could usually to two things, but never three. For many years he had been a member if a number of secret orders, but he could no longer recall the passvords. His urine contained a trace of albumin and some mucus and quamous epithelium; no casts; no sugar; it was acid, with a specific sravity of I,oIo. He liabitually drank large quantities of water.

The president, Dr. Dana, said the case shown by Dr. Meacham was 1ot presented as one of distinct aphasia, but rather as one of pre-senile dementia, although the patient lacked many of the characteristic symptoms of dementia. while on the other hand he showed many of the characteristics of mixcd aphasia. He regarded the case as a form of aphasia associated with senile denentia. The symptoms of dementia were apparently limited to the language zone. The case was certainly rather unique, especially in connection with the recent dictum of Marie that aphasia was associated with an intellectual deficit.

\title{
A CASE OF APHASIA.
}

\section{By Dr. C. L. Dana and Dr. J. Ramsay Hunt.}

The patient was a man, 45 years old, who was brought to Bellevuc Hospital on November 26 , Igo6. He was suffering from complete motor aphasia, together with a moderate degree of right hemiplegia. $\mathrm{He}$ was unable to express himself or answer the most simple questions. Upon admission, the light reactions of the pupils were somewhat stiff, and it was thought for a time that the case might be one of aphasia associated with early paresis. In the course of a few days, however, his speech disturbance began to clear up; he was able to say a few words and then a few sentences, and this improvement has been progressive. There were some sensory disturbances on the right side, which still persist in a moderate degree, and he has also evidence of a right hemianopsia. On admission, he could understand and was able to carry out single directions, such as those to close the eyes, etc.

From a friend who visited the patient at the hospital it was learned that the latter, for several weeks prior to the onset of his attack, had complained of headaches and a distinct weakness in the right leg. The patient was now able to speak fairly fluently; he was still unable to make himself understood or to name certain objects. He has alexia and agraphia. The case was regarded as one of occlusion of the posterior cerebral artery, probably syphilitic in origin. (There were large pigmented scars along the tibia in both legs, and a somewhat doubtful history of a primary lesion.)

Dr. Dana said that while this patient had fairly good voluntary speech, and while his general intelligence was excellent, there was a jargon of sentences which made his speech unintelligible. He was unable to write. He understood words and sentences, and did what he was told. His worst defect, apparently, was the anomia, which applied not onlv 
to objects seen, but also to objects felt and heard. His ability to read was absolutely gone. The case was one of pure sensory aphasia, with anomia as its dominant feature, and with it was associated agraphia, and, as was usually the case, alexia. The lesion in this case was regarded as a thrombosis, or perhaps a small hemorrhage.

In considering this general subject of aphasia, Dr. Dana said he was inclined to believe that the new theory of Marie regarding the localization of these speech disorders was really much nearer correct than the views that had been accepted by the profession for half a century or more. While these disorders were the result of a lesion in the so-called aphasic area, he believed it would be wise to either cut out the Broca convolution from the zone of language, or else regard the latter as only more or less distantly associated with the real aphasic area, and of minor importance in that connection. The frontal lobe governed, apparently, the centers for memory of the movements of articulation rather than the true centers of speech. It controlled, apparently, certain forms of disturbance of speech, such as stuttering, but was not intimately associated with the higher speech centers.

Dr. Joseph Collins said that the views of Marie seem at first sight to be more revolutionary than they are in reality. The most far reaching effects of Marie's conception are in the psychological conceptions of the development of speech and its production. There is no doubt that the schematic or diagrammatic representation of the speech areas has been carried too far, and the definiteness with which verbal memories and visual memories, and memories of movements of the spoken and written words have been allotted to certain small areas has been overdone, but this does not justify the overthrow nor the attempt at overthrow of that which has been definitely proven in regard to the localization of the different forms of memories, the awakening of which constitutes the initiation of articulate speech. Marie's views are sufficiently definite and his position in the scientific world sufficiently firm to demand that his clains be verified or denied. This verification or denial cannot be through expression of personal opinion, but by study of patients and of the lesions which are found in their brains after death. Much that Marie claims is by no means new. For instance, everyone who has much to do with aphasia will agree with him that there is in all aphasic individuals a diminution of intellectual capacity which amounts to real enfeeblement. Anyone who would claim the contrary could scarcely have an adequate conception of the enormous structural lesions that are at the basis of the particular lesion that gives rise to the aphasia. In the vast majority of cases of aphasia there is widespread arteriosclerosis, and the nutrition of the brain and its dependent psychological functions are proportionately disordered.

Although Marie has brought forward much evidence to show that many cases of so-called motor aphasia, i.e., aphasia due principally to the loss of memories of articulation, is dependent upon a lesion of the posterior areas, i.e., of the first temporal and the inferior parietal convolutions, plus anarthria; although Dr. Collins for one, was willing to admit that in some instances this condition is the one that exists and which accounts for the symptoms, still there are cases on record in which the lesion is closely limited and confined to the allotted seat of memories of articulation, viz., to Broca's convolution, and in these cases the symptoms that occurred were typical of motor aphasia. Dr. Collins 
referred particularly to the cases of Ladame and of Bernheim. One such case as either of these is as good as one hundred to demonstrate that motor aphasia may be the result of a lesion so situated.

Finally, a word in regard to Marie's conception of anarthria. First, it must be admitted that Broca's convolution sends no projecting fibers directly into the motor tract, and that therefore a lesion of Broca's area does not cause anarthria. Second, Marie's idea of anarthria and its relation to destruction of the lenticular area is not materially different from Dejerine's idea of subcortical motor aphasia, or pure motor aphasia, as he calls it. Finally the only way of settling this question is not academically, but at the bedside and at the post-mortem table, and that work we are called upon to do.

Dr. B. Onuf said that frequently, in cases of aphasia, the autopsy showed very extensive lesions, making the cases unfit for differential diagnosis, inasmuch as such lesions caused the involvement of so many functions that it was difficult to determine which part of the lesion had impaired this function or the other. As proof of this statement Dr. Onuf adduced three cases (two of aphasia and onc of dysarthria) which had been clinically observed by Dr. Fraenkel and himself, and examined post-mortem in several sections. In all three of the se cases the lesions had been very extcnsive, destroying a large part of the hemisphere.

The question of the role of the third frontal convolution, which Marie denied had any relation to the function of speech, had been carefully investigated by Drs. Fraenkel and Onuf, and embraced the study of 104 cases of aphasia, with autopsies, collected from the literature. This had shown on what a remarkably small number of clear-cut cases the view of the speech functions of Broca's region was based. Only five of the 104 cases showed a lesion confined to Broca's area, while in two cases there was a slight encroachment on adjoining regions. In all the other cases, Broca's region was either not involved, or there were marked additional lesions of other cortical regions or of the sub-cortex. Of the seven cases first referred to, only two showed clearly a lasting aphasia, while in the others it was either only temporary or not sufficiently long observed to say whether it was temporary or permanent. Nevertheless, the fact that all of these seven did show aphasic disturbances, whether temporary or permanent, was in confirmation of the importance of Broca's center for the function of speech.

To elicit further evidence regarding the function of Broca's center, Drs. Fraenkel and Onuf tabulated, graphically, all the cases of purely cortical lesions in their collection, according to the scheme of Naunym, which consisted in having the surface of the brain divided up into squares of equal size, and registering the lesions on that diagram in the following manner: Whatever squares were covered by the lesion in a particular case received one dot. If a given square fell within the domain of the lesion of a second case, that square received a second dot, and so forth, so that the squares showing the greatest number of dots indicated the greatest number of cases in which those particular regions had been affected. The result of this registration showed such a marked accumulation of dots in the region of the foot of the third frontal convolution that the view of the important role of that region for the function of speech was amply confirmed.

Marie's views regarding aphasia, as set forth in his first article, ex- 
perienced a considerable elaboration, modification and crystallization in his second article, making some things clear which did not appear so in the first article. The exact meaning, for instance, of the word "anarthria" was by no means clear from the first article, but was distinctly defined in the second one. It appeared that some of his differences of view from those of other writers were partly in name only. Anarthria, for instance, was substituted for the term aphasia motrice pure of other authors, and was acknowledged clinically but given another anatomical basis by Marie. That basis was a lesion of the so-called lenticular zone, $i . c$., of the zone consisting of the white substancc situated between the cortical convolutions of the insula and the lenticular nucleus, and of the outer layers of the lenticular nucleus itself. Marie gave no definite explanation why such lesions should cause anarthria.

The researches of Drs. Fraenkcl and Onnif, on thic other hand, encleavored not only to find an anatomical basis for the aphasia motrice pure, but also to explain the mechanism of the lesion. Their results spoke against the existence of a direct speech pathway leading from Broca's area of the internal capstile, inasmuch as lesions of the internal capsule were relatively very rare in sub-cortical cases of aphasia in the $\mathrm{IO}_{4}$ cases they had collected. On the other hand, the lesion mostly met with in those cases was one of the medullary layer of the third frontal convolution, and next in frequency the region around the upper margin of the lenticular nucleus in its anterior part was involved. This strongly confirmed their theoretical considerations that these two regions formed part of an association pathway connecting Broca's area with those centers situated at the base of the central convolution which inncrvated the muscles concerned in the function of speech; $i$. e., the muscles of the tongue, larynx, pharynx, lips, etc.; briefly, the articulo-motor muscles. They confirmed their view that Broca's center was a higher co-ordinatory center, presiding over the articulo-motor centers just mentioned. grouping those innervations of the latter which were necessary for the purpose of articulation.

Dr. Joseph Fraenkel said that by accepting Marie's views we gave up a great deal of what we had for years thouglut to be the best established truths of neuro-physiology. Personally, he did not hesitate to say that Dr. Onuf and himself had done a great deal of work in connection with aphasia, and for some reason that work had received no notice. During his residence at the Montefiore Home he had seen and thoroughly studied a goodly number of all forms of aphasia, and had witnessed the autopsies of a considerable proportion of them. As a result of this he believed:

I. That we must clcarly know and define the terms we are using, and appreciate the fact that aphasias are all disturbances of speech resulting from an interference with the psychic mechanism of speech, and that anarthrias are all disturbances of speech which are the result of interference with the somatic or mechanical mechanism of speech.

2. That there undoubtedly exist-rarely, to be sure-forms of pure motor aphasia, contical and sub-cortical.

3. That rarely would the lesions producing these forms of aphasia be so strictly localized as not to encroach upon neighboring territories, and even so, the underlying disease would to an extent interfere with the other functions of the brain, thus producing some intellectual impair- 
ment, which would appear in every case at some time or other.

4. That their investigations had shown the existcnce of the lenticular association zone, which in their belief was the sub-cortical speech path. and which led, when diseased, to what they called sub-cortical motor aphasia, and what Marie called anarthria.

In connection with Dr. Sachs' case, the speaker said he wished to mention that Edgren had shown that the musical concepts and pictures were stored in the second left temporal convolution, and that therefore the preservation of this faculty in the patient presented by Dr. Sachs was not surprising.

Dr. L. Pierce Clark said if Marie's theory that an intellectual deficit was always associated with aphasia should be proven, it might have an important bearing from a medico-legal aspect, particularly regarding the will-making capacity of apoplectics.

Dr. Saclis, in speaking of the case of aphasia he had shown, said that if Dr. Collins had been present at the time, he could not possibly have made the statement that the patient did not have sensory aphasia, or that it was simply a case of notor aphasia.

This general stubiect of aphasia, Dr. Sachs said, was one of the utmost importance, and in spite of the statement made by Dr. Collins, and the quotation from Marie's recent article, the reference made by that writer to an intellectual defect in aphasics was not very clear, particularly from a psychological point of view. Personally, he believed Marie meant that the defect was entirely in the conception and perception of speech, and did not necessarily imply a distinct mental defect. Mental deterioration could be safcly denied in a large number of cases of aphasia, and the spcakcr citcl such a casc that was at present under his observation at Mt. Sinai Hospital. The case was one of motor aphasia, pure and simplc, in a man of considerablc intelligence, and there was not a single indication of any mental deterioration.

In a close analysis of cases of motor aphasia, Dr. Sachs believed that the chief difficulty was not connected with the concept movements, but was simply a difhculty in directing the movcments of speech. He thought there were very few cases in which the actual conception of movements that were necessary to effect articulation was absent; the difficulty was simply an inability to use the organs of speech. He was perfectly willing to substitute the word anarthria for the French term aphasia motrice pure, and if that was to be the outcome of Marie's doctrine, he considered it a distinct step in advance. It was unfortunate, he thought, that the work of Onuf and Fraenkel in connection with aphasia had not receiverl more general attention.

Dr. Dana said that this subject of aphasia would probably come up before the Society for discussion again at some future period, and that at present it was impossible to arrive at any absolute conclusion regarding it. The entire question should be taken up in a receptive mood, and carefully re-studied. In the course of his teaching. Dr. Dana said, he liaf at times been somewhat embarrassed by the practical inutility of the older methods of presenting the subject of aphasia, and he had never been quite able to mike the text-book descriptions of these speech disorders tally with his clinical findings. He was inclined to agree with those who believed that the entire subject should be studied from a little different point of view, which implied, essentially, that the cases should be studied as we saw them. We practically never saw cases of either pure 
motor or pure sensory aphasia, and it was very difficult to explain this difference to students.

Dr. Dana said he agreed essentially with the views expressed by Dr. Sachs that the Broca convolution was not in the same class as the rest of the zone language; that it was of a lower type, and while cortical disease in that region might cause aphasia, it was a loss of articulation and not of the concept of language. He did not like the term anarthria.

\section{ADDRESS OF THE RETIRING PRESIDENT.} By Dr. Joseph Fraenkel.

The retiring President, in a brief address, thanked the members of the Society for their support during the past year. He said that the gloomy views that had been held out in regard to neurology in recent years had not been realized: on the contrary, the outlook in this branch of medical science was brighter than ever, particularly in connection with the clinical investigation and study of function, a field that had been too much neglected in the past.

\section{ADDRESS OF THE INCOMING PRESIDENT.}

By Dr. Charles L. Dana.

Dr. Dana said that since his first experience in that office there had been many intensely interesting phases in the evolution of modern neurology. The finer anatomy of the nervous system was then a matter of active discussion, because it was just being unfolded. The exploitation of the neurone theory, the localization of the cortical and spinal functions, the changed views of neuro-pathology, the better descriptions of the various nervous diseases, the new diagnostic methods and signs and the portrayal of new types furnished a constant succession of interesting themes and topics for discussion. There was now a feeling that all of this was more or less completed, at least in its larger outlines, and to a certain extent this was true, but it was no more true than for other specialties, or even for internal medicine.

Dr. Dana said that all over the world where neurological societies existed he had found that the main body of the work was in the clinical presentation and study of cases, and this was the line along which the New York Neurological Society would have to continue. We could not tell at what moment the deeper knowledge of physical forces, of chemistry, radio-activity, etc., would evolve new problems and rich illunination. The time had come when the neurologist had to keep in closer touch than ever before, perhaps, with the laboratory, especially in the solution of functional neuroses and psychoses.

Among other topics touched upon by Dr. Dana in his address was the duty of the neurologist in relation to public economic questions; the great necessity for a hospital for nervous diseases in New York City, especially for the middle classes; a study of the nervous and mental diseases incident to our American mode of life; nervous diseases and diseases in general in relation to the occupations of the poor; and the proper enlightenment of the public in regard to the evils of the various forms of faith cure and charlatanry. The speaker said he looked upon the psychic side of neurology as still quite a fresh field. There was a whole world of subjective complaints that had heretofore been dismissed with impatience, but which really deserved 